


\title{
Editor-in chief
}

Editor-in-Chief Gülaçtı Topçu

Co-Editor-in-Chief Ahmet C Goren

\section{Editors}

\author{
Erkan Baloğlu \\ Erdal Bedir \\ Nezhun Gören \\ David G.I. Kingston \\ Süheyla Kırmızıgül \\ Temel Özek \\ Atta-ur Rahman \\ Hasan Seçen \\ William N. Setzer \\ Olga Tzakou \\ Jenny M Wilkinson
}

Kemal H. C. Baser

Ihsan Çalış

ilhami Gülç̣in

Turgut Kılıç

Ufuk Kolak

Franco Piozzi

Bernd Schneider

Bilge Şener

Gülaçtı Topçu

Rob Verpoorte

Nurettin Yaylı

\section{Language Editors}

William N. Setzer

Zeynep Sadak

\section{Abstracting \& Indexing}

Records of Natural Products is abstracted and Indexed in: Chemical Abstracts Service, CAB Abstracts, EMBASE, EMBiology, Index Copernicus, ProQuest; EBSCOhost, SCOPUS, Crossref, ISI Alerting Service; Chemistry Citation Index (CCI) and Science Citation Index-Expanded (SCl-E), $i$-Journals; $i$-Focus.

\section{Publisher}

\section{ACG Yayıncılık Basın Yayın Sanayi ve Ticaret Limited Şirketi}

Yenikent Mahallesi, Fırat Caddesi, 1/3, Gebze, Kocaeli, İstanbul, Türkiye

+90850305 0572 - www.acgpubs.org - info@acgpubs.org

2019 @ ACG Publications. All Rights Reserved

\section{Instruction For Authors}

\section{Preparation of Manuscripts}

Manuscripts should be prepared in English using a word processor.

Authors must use templates (Template file for original article:Please click to open template file) or (Template file for short report:Please click to open template file) for the preparation of manuscripts. The template offers the authors many features that ease manuscript preparation and submission; all graphics and Tables can be integrated into the manuscript where the author wishes to place them. Requested supporting information must be prepared as shown in the template of supporting information:Please click to open template file.

The essential oil and fatty acids and related papers should be prepared according to requested rules which is described in the 
following link"Guide for essential oils, fatty acids and related studies: please use the appropriate template file which are given above for essential oils, fatty acids and related studies as well".

Novelty statements of submitted manuscript must be provided as MS word file item by item. The maximum item should be 6 for the novelty statement.

A graphical abstract must be provided during submission. The dimensions of the graphical abstract must be $6.5 \mathrm{~cm}(\mathrm{~h}) \mathrm{x}$ $12.5 \mathrm{~cm}(\mathrm{I})$. Please do not use the portrait version of graphical abstract. The graphical abstract must briefly show the contents of the abstract. Only structure of compound or picture of species not allowed for the graphical abstract.

For new compounds: New compounds search report of SciFinder should also be uploaded via the supporting information document system in PAMS.

Review Articles are critically evaluated on the specific area in natural product chemistry. If you would like to contribute to the journal with a review article, the authors must initially contact the editorial office by email to info@acgpubs.org, as such articles are normally invited.

Original Articles are manuscripts describing structure elucidation novel compounds, synthesis of naturally occurring compounds and biological activities of natural compounds, as well as new analytical methods (analytical methods must include method validation and uncertainty evaluation parts in the main text and the details must be given in the supporting information file), chemotaxonomic investigations, chemical ecology, and biotechnology. Articles that do not contain new compound(s) and that only reveal the structure analysis of known substances are not accepted as original articles. Articles that contain only one new substance and do not contain previous activity results for the species/or substances studied in the literature should be submitted as a short report article. These manuscripts should reflect completed investigations rather than fragmentary parts of a larger study. In order to reduce manuscript length, specific experimental details, NMR and HRMS (please check for the sample) spectra must be made available as supplementary material from the corresponding author for new compounds.

Short Reports are suitable for reporting known metabolites from new biological sources with discussion of biological activity and chemotaxonomic discussion, essential oil compositions, and new activities of known compounds. Manuscripts describing routine bioactivity screening (e.g., antimicrobial, antioxidant, antifeedant, etc.) of crude extracts or predictable and/or unexceptional bioactivity (e.g., antioxidant activity of polyphenolics, antimicrobial activity of essential oils), are generally not acceptable. Short Reports should be kept to a maximum of six (6) pages, including references. In order to reduce manuscript length, specific experimental details and NMR and HRMS spectra must be made available as supplementary material from the corresponding author or new compounds. The short report articles should not have more than 25 references.

Special Issues and Book reviews are collections of articles on the specific topics in areas related to aims and scope of journals published in the journal. Offers for the special topics must be applied to the editorial office.

As the manuscript language is English, any author who is not fluent enough in English is encouraged to consult a fluent colleague or a paid editing service for the preparation of the manuscripts. Manuscripts having language deficiencies, i.e. grammar, fluency, etc., create heavy problems during the review process. Such manuscripts might be returned to the authors for correcting the language deficiencies.

Manuscripts submitted to ACG publications are routinely screened by a software to check the originality of the submitted articles. It should be noted that ACG publications are committed to deterring plagiarism and selfplagiarism. Manuscripts submitted to ACG publications are routinely screened by a software to check the originality of the submitted articles. It should be noted that ACG publications are committed to deterring plagiarism and self-plagiarism. A plagiarism report must be uploaded during submission of manuscript.

Title of the manuscript should be as brief as possible and typed to the template file with affiliation and addresses of all the authors, including corresponding author with an asterisk. ORCID 1 of all authors should be added as shown in the template of manuscripts. The e-mail address, phone and fax numbers of the corresponding author should be provided as a footnote on the title page. Abstracts of all kinds of submissions should be prepared with a maximum 200 words.

Manuscripts should be compiled in the following order: Manuscripts should be compiled in the following order: Title page; Abstract; Graphical abstract (in PAMS only), Keywords; Introduction, Materials And Methods, Results and Discussion, Acknowledgments; Appendixes (as appropriate); References; using a decimal system for subsections. Novelty statements of manuscript must be provided and authors must adhere to SI units. When using a word which is or is asserted to be a proprietary term or trade mark authors must use the symbol ${ }^{\circledR}$ or TM or alternatively a footnote can be inserted using the wording below: Please see the details of section to the following link "Guide for manuscript preperation".

\section{References}

References should be cited in the text by Arabic numbers in square brackets and should be arranged in the list of references according to the numbers in the end of the main text. Unpublished results and personal communications should not be in the 
reference list, but may be mentioned in the text. If reference is made to papers submitted or in press, authors are requested to enclose a copy of manuscript or galley proof.

The following examples illustrate the format for reference:

Journal citation

A.C. Goren, B.N. Zhou and D.G.I. Kingston (2003). Cytotoxic and DNA damaging activity of some aporphine alkaloids from Stephania dinklagei, Planta Med . 69, 867-868.

\section{Chapter citation}

A. Ulubelen and G. Topcu (1992). Diterpenoids from Salvia species and their pharmacological activities, In: Studies in Natural Products, ed: Atta-ur Rahman, Elsevier Science, Amsterdam, Netherlands, pp.363-381.

Book citation

R.P. Adams (1995). Identification of essential oil components by gas chromatography/mass spectroscopy. Alluredpublishing Co. Carol Stream, Illinois.

\section{Plagiarism Check and Ethics}

Any manuscript submitted, soon to be submitted or in press at any other journal will not be considered by Records of Natural Products (RNP), and it is authors responsibility to inform the Editor of Records of Natural Products if such event exists. If the submitted manuscript is a revised version of a previously rejected by RNP, the authors must indicate previous submission in their cover letter and explain the reason/changes that they made in the revised one.

The Ethical Guidelines for Publication in Journals and Reviews issued by the European Association of Chemical and Molecular Sciences are applied by Records of Natural Products. Authors of all the manuscripts submitted to Records of Natural Products automatically accept the guidelines given in the Ethical Guidelines for Publication in Journals and Reviews and the authors have to provide the ethical board approved document informations ( the number and date and ethical board name of ethical approval) in the main text of manuscript and related data should be available in supporting information file of manuscript, if necessary or requested by the editorial office. The following studies strongly needs ethical board approval eg. any of in vivo studies on any animal and human body, studies of endangered species in nature, information about the people including any kind of survey data etc. For detail please see the COPE guidelines.

Authors are encouraged to attach an authenticated report during the submission to make sure that there is no plagiarism problem. Manuscripts submitted to Records of Natural Products publications are routinely screened by a software to check the originality of the submitted articles. It should be noted that RNP publications are committed to deterring plagiarism and selfplagiarism

ACG Publications journals use iThenticate ${ }^{\circledR}$ software to check the originality of submitted manuscripts for plagiarism. If a duplication is detected by the editorial office and reviewers, the manuscript will directly be rejected. If the authors use the same sentences of their or another author's previous work with citation without quotation mark, it will still be considered as self-plagiarism and plagiarism, respectively. Records of Natural Products has the right of removing any article published in RNP, and banning the authors submitting their studies in future if any ethical violation is identified.

\section{Copyright}

It is a condition of publication that authors vest or license copyright in their articles, including abstracts, in ACG Publications. This enables us to ensure full copyright protection and to disseminate the article, and the Journal, to the widest possible readership in electronic formats as appropriate. Authors must accept the articles published in the journal for free all around the world. To read and download published papers is free for scientific purposes.

\section{Supplementary Material}

Supplementary materials could be sent together with manuscript submission such as spectra, video, Picture etc.

\section{Publication Fee}

Current (2022) publication fees for the different kinds of articles are given below.

$\begin{array}{lll}\text { Article Type } & \text { Number of Pages } & \text { Publication fee } \\ \text { Review Article } & 1-50 & 750 \text { USD } \\ \text { Book Reviews } & 1-2 & 300 \text { USD } \\ \text { Original Articles } & 1-20 & 750 \text { USD } \\ \text { Short Reports } & 1-6 & 600 \text { USD }\end{array}$


*\% VAT is included, bank commission should be applied to payments.

**No submission fee applied by ACG Publications journal. APC is only applicable for the accepted articles.

Withdrawal of a Manuscript: If you intend to withdraw your manuscript after it has been peer reviewed, or after it has been typeset, but not yet published, you will be asked to pay according to the following:

For peer review:200 USD per article

For peer review and typesetting: 300 USD per article

Considering the primary aim of RNP, waivers are available for the authors who are the least developed countries. To apply to those options, the corresponding author and $80 \%$ of the authors of the concerned manuscript must be from those countries and the study must be conducted in the least developed countries. Please visit the page concerning the list of these countries; https://www.un.org/development/desa/dpad/least-developed-country-category/ldcs-at-a-glance.html . If you have any difficulties about this issue please contact the editorial office. APC only available for accepted articles in ACG Journals and no fee required during the submission of manuscript.

The authors are charged a fee for English language corrections and/or journal format corrections requested by the authors or editorial team. These services are not considered within the free publication criteria of related journals of ACG PUBLICATIONS.

\section{Proof Corrections}

The proof corrections must be done carefully by the authors. When proof corrections are returned to Journal further corrections are not allowed, after the peer review process.

Erratum or Publisher Correction. Notification of an important error made by the journal that affects the publication record or the scientific integrity of the paper, or the reputation of the authors or of the journal.

Corrigendum or Author Correction. Notification of an important error made by the author(s) that affects the publication record or the scientific integrity of the paper, or the reputation of the authors or the journal.

Retraction. Notification of invalid results that affect the reliability of a previously published article. The original article is marked as retracted but remains available to readers, and the retraction statement notifying readers of the invalidity of the published paper is bi-directionally linked to the original published paper.

Addendum. Notification of additional information about a paper. Addenda are published when the editors decide that the addendum is crucial to the reader's understanding of a significant part of the published contribution. Addenda include Editorial Expression of Concern, which is an editorial statement alerting our readership to serious concerns with the published paper. Editorial Expressions of Concern are typically updated with another amendment once further information is available. The editors may request additional information after publication of the article from the authors and it can be available on the page of the article.

\section{Peer Review Policy}

All published research articles in Records of Natural Products have undergone rigorous single blind peer review, based on initial editor screening and anonymized refereeing by expert referees. 


\section{Contents}

Original Article

Kui-Wu Wang, Xiaoxin Wang, Haijiang Zhang and Yichao Ge

A New Aporphine Alkaloid from Illigera aromatic - p.440-445

Original Article

Hatıra Taşkın, Zeynep Dilan Çelik, Fuat Bozok, Turgut Cabaroğlu and Saadet Büyükalaca

First Report on Volatile Composition of Tricholoma anatolicum in Comparison with Tricholoma caligatum - p.446-455

Original Article

Can Su, Chongxi Liu, Yongjiang Wang, Wen-Sheng Xiang, Chenggang Zou and Sheng-Xiong Huang

A New Heliquinomycin Analogue with Immunosuppressive Activity from Streptomyces sp. jys28 - p.456-461

Original Article

Xuesong Liang, Dewen Bi, Fengqiu Li and Liqin Wang

Chemical Compounds from the Twigs and Leaves of Caesalpinia cucullata Roxb - p.462-467

Original Article

Qin Ren, Zhenxing Zou, Yang Liu, Xi Chen, Kangpin Xu and Guishan Tan

Two New Lignans from Lycopodium japonicum Thunb. - p.468-474

Original Article

Zhenggang Yue, Rui Zhou, Yihan He, Hongbo Xu, Yalei Pan, Liyan Lei, Pei Xie, Zhishu Tang and Jinao Duan

Protein Tyrosine Phosphatase 1B Inhibitors from the Root Bark Pseudolarix amabilis (Nelson) Rehd. (Pinaceae) -

p.475-482

Original Article

Qiyan Li, Yan Wang, Songsong Wen, Ying Wu, Lihua Xu and Zhenliang Sun

A New Dimeric Sesquiterpenoid from Chloranthus japonicus - p.483-490

Original Article

Parinuch Chumkaew, Passakorn Teerapongpisan, Jaraslak Pechwang and Theera Srisawat

New Oxoprotoberberine and Aporphine Alkaloids from the Roots of Amoora cucullata with Their Antiproliferative Activites -

p.491-498

\section{Original Article}

Xin Zhang, Jing Sun, Shuo Zhang, Yafeng Yan, Rongxin Zhang, Xuanji Xue and Zengjun Guo

Two New Cholestanol Glycosides from the Roots and Rhizomes of Smilacina henryi - p.499-505

Original Article

Kangkang Mei, Guokai Wang, Heping Cai and Baixiang Cai

Cephalounei A, a New Cephalotaxus Alkaloid from the Powdered Stems of Cephalotaxus fortune Hook. f - p.506-511 